\title{
Politicians and scientists
}

\author{
The restructuring of the NHS has no basis in scientific research
}

At the heart of the current dissent between the government and the health professions about the changes being imposed on the NHS is the concept of scientific method. This century doctors, nurses, and medical scientists have learnt the hard way that the best way of improving performance and outcome is to do some research, identify the faults, design a new approach, evaluate it - and adopt it generally only when it is proved superior to the existing system. Furthermore, scientists (but not, it seems, politicians or civil servants) are aware that the essential property of a scientific hypothesis is its falsifiability and that research evaluation should mean trying to prove the theory to be wrong.

Set against these criteria the white papers on health service reforms fail on every count, ${ }^{12}$ and their failures have now been spelt out in detail in the Rock Carling lecture given this week by Gordon McLachlan, who has spent a professional lifetime (after training as an accountant) in health care, working firstly in the NHS and later for 30 years as secretary of the Nuffield Provincial Hospitals Trust. ${ }^{3}$

The main charge he makes is that the white papers seem to have been based on dogmatic beliefs rather than any research analysis. "One looked in vain for the soundness of the bases for the really contentious items-GP budgets and the hospital trusts - and wondered to what rigorous tests they had been or would be subjected." Commenting on an earlier Rock Carling lecture by Sir Kenneth Stowe ${ }^{+}$(formerly permanent secretary at the DHSS), McLachlan criticises the policy makers for their introverted attitudes-"Whitehall turntable circling round the Great George Street citadel"-and the lack of any close or scientific observation of the NHS as it has evolved. Indeed, the main problem with the repeated attempts by successive governments to restructure the NHS has been the lack of any reliable source of essential data; the amount of systematic research into its own functions by the NHS has been derisory ever since its foundation. No commercial business the size of the health service would expect to function without a large investment in research and development; the lack of any such programme is a serious criticism of the Department of Health. The announcement earlier this month by $\mathrm{Mr}$ Kenneth Clarke that he is at last to appoint a director of NHS research is welcome-but very late. ${ }^{5}$ The new director will have a seat on the NHS Management Executive and will be given substantial autonomy - but will his staff be as big and well financed as in a comparable organisation in the private sector?

But, of course, the NHS is not in the private sector-and the overwhelming majority of its workforce do not want it to be. The second penetrating criticism of the government's plans and their architects made by Gordon McLachlan is that they do not seem to have appreciated "that there is a strong vocational element motivating those directly concerned with health services." Doctors, nurses, and other health workers have worked long hours, often in depressing environments, without too much complaint because the NHS has had no commercial ethic. The government's proposals now seem to be based, McLachlan points out, on a political ideology that makes pecuniary incentives the means of improving cost-benefit relations-but without any clear idea of what "benefit" entails or how to measure it. Experience in the United States has shown some of the difficulties of assessing benefit in the setting of health care: prolonged survival in chronic disease is necessarily more expensive than short survival but it is what the consumer wants. Already talk among administrators in North America is that the 1990s may be the postcompetitive era in health care.

McLachlan draws an apt analogy between the government's proposals for the NHS and the poll tax. The problems encountered in introducing the tax might have been foreseen by careful policy analysis, and the same seems likely to be true of NHS reforms. Both the poll tax and the NHS reforms are new theoretical solutions to longstanding problems, and both are based on political convictions rather than adequate research. Both have been opposed by the staff expected to introduce and operate the new systems, and both have reduced morale in the organisations concerned. Both are claimed to herald an era of greater cost effectiveness; but in reality both conceal the deep abhorrence of the current administration for public spending and its conviction of the merits of a low tax, low welfare society.

And when historians bring in a final verdict on the 1980s it seems likely that they will point to the great opportunity missed: the $£ 65$ billion from oil revenues and $£ 23$ billion from privatisation sales could and should have been used to finance rebuilding and modernisation of health care and education. ${ }^{6}$ Instead this vast-and once only-capital sum was used to lower taxes. Britain has the oldest and most decrepit hospitals and schools in western Europe. We could have transformed them.

"But we are spending more than ever on the NHS," say $\mathrm{Mr}$ Clarke and his colleagues when criticised for the parlous state of health finances. So they should be. As countries become more prosperous they spend a greater proportion of their 
greater wealth on health care - the United States now spends 15 times as much as Britain, though its population is only four times greater. McLachlan reiterates the basic economic facts: measured by per capita spending Britain has one of the cheapest health care systems in the world. And it is this highly effective system that is now to be transformed for reasons of ideology.

Should it not by now be obvious that the immediate prospect for the NHS is that it will be disrupted and disheartened over the next two years as its staff struggle to introduce new control and costing systems without the essential accounting infrastructure? Every health region is installing information systems and hiring accountants and computer programmers while closing beds and cutting down the numbers of outpatient clinics (including specialist clinics such as family planning clinics). ${ }^{7}$ The NHS is steaming full ahead into an iceberg that will prove as devastating as the one that sank the Titanic. McLachlan is only the latest in a series of well informed and articulate commentators who have drawn attention to a forseeable disaster. Is there no one on the bridge prepared to order the engines to slow - or, even better, go full astern?

Deputy editor, $B M \mathcal{F}$

TONY SMITH

1 Secretaries of State for Health, Wales, Northern Ireland, and Scotland. W'orking for I'utients. London: HMSO, 1989. (Cmnd 555.)

2 Department of Health and Welsh Office. General Practice in the National Health Service. A new contract London: DoH 1989.

3 McLachlan (i. What price quality? The NHS in review. Rock Carling Fellowship 1990. London: Nufficld Provincial Hospitals Trust, 1990.

Stowe K. On caring for the national health. Rock Carling Felloweship 1989. London: Nuffield Provincial Hospitals Trust, 1989.

Provincial Hospitals Trust, 1989.
Warden J. New deal for medical research. Br.Med f 1990;300:1159.

5 Warden J. New deal for medical research. Br. Med f 1990;300:1159.
6 Linton M. Brown attacks big trade deficit and ridicules "sunset Tories." Guardian 1990 March $7: 4$ cols $2-6$

7 Smith T. Unwanted pregnancies. Br.Med f 1990;300:1154.

\section{Central pain}

\section{Much can be offered from a methodical approach}

Central pain is the term used for pain arising from lesions confined to the central nervous system and of an intense unbearable nature. It is often associated with particularly unpleasant dysaesthesiae. It may be either diffuse or localised; it may be spontaneous or occur in response to minor stimulation, but it is usually associated with overreaction to stimulation. Sensory impairment or loss is invariable.

The definition of central pain is not, however, without some ambiguity. Some pain clearly has a mixture of a peripheral and a central cause - for example, the pain in arachnoiditis where peripheral lesions occur and where there is a central lesion as shown by the presence of long tract signs. Each year more research shows that peripheral mechanisms induce central changes, and the division between central and peripheral pain is necessarily becoming blurred. Nevertheless, Cline $e t$ al have shown in humans sensitisation of $\mathrm{C}$ nociceptors with low threshold and prolonged discharges after sensitisation (which would explain the abnormal quality of pain and exaggerated response in patients with chronic pain) but with no evidence of secondary dysfunction of the central nervous system or sympathetic disturbance. ${ }^{1}$ There remain, therefore, considerable uncertainties about the mechanisms of both central and peripheral pain.

One of the best known categories of central pain is the thalamic syndrome, which is usually due to ischaemic or haemorrhagic vascular lesions or arteriovenous malformations. Less commonly it may follow trauma, including surgical lesions of thalamus, and relatively infrequently it may be due to a tumour. Bowsher et al have recently drawn attention to an important and often overlooked cause of central pain. ${ }^{2}$ They described seven patients in whom subarachnoid haemorrhage (one from arteriovenous malformation) was followed by pain and discussed further cases after stroke other than intracranial haemorrhage. In most of the patients there was no evidence of delayed ischaemia and the central pain seemed to be due to primary neurological damage occurring at or soon after the haemorrhage. Their patients showed the classical features of central pain: it took time to develop, there was no tissue damage outside the central nervous system - as is the case in nociceptive (tissue damage) pain-and there was an associated sensory deficit. Furthermore, the patients showed allodynia - that is, the production of pain by a non-painful stimulus (pathognomonic of neurogenic pain), lower skin temperatures in the painful area with the frequent exacerbation of pain by temperature changes or emotional stress (suggesting autonomic activity), and resistance to analgesia with narcotic drugs.

Painful syndromes in the spinal cord may be due to vascular lesions or to trauma. In complete lesions phantom sensation or phantom pain occurs in a way similar to the description of phantom limb after amputation; it may be referred to any part of the body below the transection but is usually referred to the legs or the feet. In an incomplete lesion (such as a BrownSéquard lesion) the pain is short lived on the side of the lesion but may persist for years on the contralateral side. Pain may occur with syringomyelia, and it may precede any other sign of the disease by many years. In patients with multiple sclerosis pain and dysaesthesia is not unusual, although frequently the patients do not report the pain unless questioned. Lhermitte's sign is usually associated with discomfort rather than pain.

The localised pain (sometimes of nerve root distribution) seen in patients with spinal tumours is not strictly pain of central origin. Painful dysaesthesia may, however, refer to areas below the level of the lesion and in rare cases pain may precede any other symptom or sign. Less common causes of central pain include myelitis and myelopathy due to cervical spondylosis.

Paradoxically, surgical lesions designed to alleviate pain, such as cordotomy and commissural myelotomy, may produce late unpleasant pain; this is often quite different from the original pain and is associated with dysaesthesia.

Suprathalamic lesions may give rise to pain that is similar to the pain of the thalamic syndrome.

\section{Pathophysiology}

The nociceptive system (nociceptive because it responds to noxious stimuli) has a complex and widespread organisation. As pain for most people is a minor event this system must either be concerned in other and perhaps more important aspects than signalling pain (for example, it may be concerned with inflammation or tissue repair) or it must be almost continuously suppressed in normal circumstances. Central 